\title{
Obstructive Sleep Apnea Educational Intervention of Dental Hygiene Students
}

\author{
Kathrine Glueckert RDH, MSDH ${ }^{1}$; Sarah Jackson RDH, MSDH²; Ann O’Kelley Wetmore, RDH, MSDH²; Roberta Snover, MS, DrOT, \\ $\mathrm{OTR} / \mathrm{L}^{3}$
}

\begin{abstract}
${ }^{1}$ Bachelor of Science in Dental Hygiene Degree Completion Program, Eastern Washington University, Spokane, Washington; ${ }^{2}$ Department of Dental Hygiene, Eastern Washington University, Spokane, Washington; ${ }^{3}$ Department of Occupational Therapy, Eastern Washington University, Spokane, Washington.
\end{abstract}

\begin{abstract}
Study Objectives: Oral health professionals (OHPs) have a unique opportunity to screen for obstructive sleep apnea (OSA) but receive limited education about OSA. This study determined whether an online educational intervention could significantly increase the knowledge of information relevant to OSA screening in individuals studying dental hygiene (DH). ${ }^{1}$

Methods: A 17-question, comprehension-based pretest and posttest assessed OSA knowledge. The convenience sample consisted of students enrolled in the first year of the DH program at Eastern Washington University in 2017. Participants completed the pretest, viewed the OSA educational video, completed a posttest, and then completed a second posttest 2 weeks following completion of the educational module. Pretest and first posttest answers were compared to determine a change in knowledge. First posttest and second posttest answers were compared to evaluate knowledge retention. ${ }^{1}$

Results: Thirty-three participants completed the pretest and posttest, and $28(85 \%)$ completed the second posttest. Participants had a significant improvement in first posttest scores $(\mathrm{p}<.001, \mathrm{t}(33)=9.836)$ and second posttest scores $(\mathrm{p}<.001, \mathrm{t}(28)=5.653)$ compared to pretest scores. Following completion of the online educational module, all participants $(\mathrm{n}=33)$ indicated they believed screening for OSA was important, and $76 \%$ of participants $(n=25)$ indicated they were likely or very likely to evaluate adult patients for OSA. ${ }^{1}$
\end{abstract}

Conclusions: An online OSA educational module is an effective educational strategy to increase students' knowledge of OSA.

Keywords: computer-assisted instruction; dental hygiene; education

Citation: Glueckert K, Jackson S, Wetmore AO, Snover R. Obstructive Sleep Apnea Educational Intervention of Dental Hygiene Students. J Dent Sleep Med. 2019;6(3)

\section{INTRODUCTION}

Obstructive sleep apnea (OSA) is a sleep disorder that has the attention of oral health professionals (OHPs). It is characterized by multiple occurrences of complete or partial upper airway obstruction during sleep. ${ }^{2}$ OSA is often identified by sleeping partners, who observe an alteration in their partner's breathing and snoring, as well as reports of excessive daytime tiredness. ${ }^{2}$ Several associations exist between OSA and other health conditions, including hypertension, stroke, diabetes mellitus, and various cardiac conditions. ${ }^{3}$ Prominent risk factors for OSA include obesity, aging, male sex, menopause, and African American race. ${ }^{2}$ Additionally, a recent systematic review and meta-analysis determined evidence of a plausible association between OSA and periodontal disease. ${ }^{4}$

OHPs have a unique opportunity to screen for OSA, because they typically spend substantial time in close proximity with patients. ${ }^{5}$ Simple screening methods are available to identify patients at high risk for OSA, including the Berlin Questionnaire (BQ), Epworth Sleepiness Scale (ESS), STOP-BANG questionnaire, and Wisconsin Sleep Questionnaire. Characteristics of OSA screening questionnaires are described in Table 1. Research suggests the time currently dedicated to OSA education is insufficient to produce OHPs who are prepared to screen for OSA. ${ }^{6}$ Thirty-two percent of dental hygiene $(\mathrm{DH})$ programs report some OSA education in their curriculum, and only 5\% report inclusion of OSA screening methods. ${ }^{6}$ These research findings suggest that supplemental education may be necessary to prepare OHPs to screen for OSA. In a 2014 study, a sample of nurse practitioners experienced significant improvement in posttest scores as compared to pretest scores following the completion of an online OSA educational program. ${ }^{7}$ For the current study, a multidimensional educational intervention was developed to answer the following question: Can an online educational intervention significantly increase the knowledge of information relevant to OSA screening in DH students?

\section{METHODS}

The Institutional Review Board for Human Subjects Research at Eastern Washington University (EWU) approved this study (HS-5174). A mixed method, onegroup, pretest/posttest design determined if an online educational intervention increased $\mathrm{DH}$ students' knowledge relevant to OSA screening.

The educational module contained general OSA content, including prevalence and risk factors as well as 
Table 1. Characteristics of obstructive sleep apnea (OSA) screening questionnaires.

\begin{tabular}{|c|c|c|}
\hline Questionnaire Title & Description of Questionnaire & Scoring Method \\
\hline Berlin Questionnaire & $\begin{array}{l}\text { Three categories (snoring, tiredness, } \\
\text { high blood pressure) with a total of } \\
10 \text { questions. }\end{array}$ & $\begin{array}{l}\text { Each category is scored separately } \\
\text { based on scoring criteria. High } \\
\text { risk if two to three categories are } \\
\text { scored as "positive." }\end{array}$ \\
\hline $\begin{array}{l}\text { Epworth Sleepiness } \\
\text { Scale }\end{array}$ & $\begin{array}{l}\text { Total of eight questions regarding } \\
\text { the probability of falling asleep in } \\
\text { different conditions. }\end{array}$ & $\begin{array}{l}\text { Likert-type scale }(\text { low }=1, \\
\text { moderate }=2, \text { high }=3) . \text { High risk } \\
\text { if total score is } 10 \text { or greater. }\end{array}$ \\
\hline $\begin{array}{l}\text { STOP-BANG } \\
\text { Questionnaire }\end{array}$ & $\begin{array}{l}\text { Contains four subjective (STOP: } \\
\text { Snoring, Tiredness, Observed apnea, } \\
\text { and high blood Pressure) and four } \\
\text { demographic (BANG: BMI, Age, } \\
\text { Neck circumference, and Gender) } \\
\text { questions. }\end{array}$ & $\begin{array}{l}\text { High risk if three or more } \\
\text { questions are answered as "yes." }\end{array}$ \\
\hline $\begin{array}{l}\text { Wisconsin Sleep } \\
\text { Questionnaire }\end{array}$ & $\begin{array}{l}\text { Questions regarding habitual } \\
\text { snoring, loud snoring, and breathing } \\
\text { pauses during sleep. }\end{array}$ & $\begin{array}{l}\text { High risk if individuals report } \\
\text { snoring sometimes (or more } \\
\text { frequently), snoring loudly, or } \\
\text { witness breathing pauses. }\end{array}$ \\
\hline
\end{tabular}

methods of OSA diagnosis and treatment. The BQ, ESS, and STOP-BANG Questionnaire were demonstrated using video recordings. A topical outline of the OSA educational module is provided in Table 2. The pretest/posttest consisted of 17 multiple choice items, including questions based on 2 case studies. The pretest and posttest were identical, with the exception of one Likert-type item and two open-ended questions added to the posttest. This format allowed for a statistical evaluation of gained knowledge and was adapted with permission from the pretest/posttest used in the research of an OSA educational module for nurse practitioners. ${ }^{7}$ Content of the pretest and posttest is described in Table 3. The posttest was taken twice, once directly following completion of the educational module, and again 2 weeks following completion to measure retention. To establish content validity, the pretest/posttest and educational module were reviewed by a thesis committee; all DH graduate faculty at EWU; and the past president of the American Sleep and Breathing Academy, Dr. Erin Elliott, DDS. Students completed a demographic questionnaire with the pretest, and a program evaluation with the first posttest. The demographic questionnaire gathered descriptive data about participants regarding their age, sex, ethnicity, education, and family history of OSA. The program evaluation gauged the participants' interpretation of the quality of the module and of the presenter using Likert-type items.

This study used a convenience sample of students enrolled in a Commission on Dental Accreditation- accredited Bachelor of Science in Dental Hygiene program. The sample population consisted of first-year DH students $(N=40)$. At the time of the study, the principal investigator was a graduate student at EWU who had no academic influence on participants. For results to have $80 \%$ power with a $95 \%$ confidence level, 32 participants $(n=32)$ were necessary. Of the 40 potential participants, the principal investigator enrolled 33 students $(n=33)$ in the research study. Of the seven excluded, two did not consent to their data being used for research purposes, three failed to submit both the pretest and first posttest, and two used the same identification number. Of the 33 participants included, 32 completed the demographic questionnaire $(n=32), 27$ completed the program evaluation $(n=27)$, and 28 completed the second posttest $(n=28)$. Of the participants who completed the demographic questionnaire $(n=32)$, most were white/Caucasian females, age 18 to 22 years, with an associate degree the highest level of education, and no immediate family history of OSA.

The OSA educational module was required as course content, but consent to the use of anonymous assessment data for research and publication purposes was voluntary. The course instructor assigned students a random identification number. The researcher did not have access to data that corresponded students' names to identification numbers. Canvas $\bigodot$ learning management system hosted the delivery of the online module. SurveyMonkey(C) facilitated assessments. Microsoft PowerPoint presentations using the record slide show function allowed 
Table 2. Topical outline of obstructive sleep apnea (OSA) educational module.

\begin{tabular}{|c|c|c|}
\hline $\begin{array}{l}\text { Time Spent } \\
(\text { min) }\end{array}$ & Topic & Subtopic(s) \\
\hline $2: 33$ & Introduction/What is OSA? & $\begin{array}{l}\text { Learning objectives, definition of OSA, OSA } \\
\text { classification, and common symptoms }\end{array}$ \\
\hline $18: 47$ & OSA Background Information & $\begin{array}{l}\text { Associated health conditions, potential } \\
\text { consequences of untreated condition (economic } \\
\text { impact, sleep deprivation safety risks, and mental } \\
\text { health/depression), risk factors, and epidemiology }\end{array}$ \\
\hline $5: 53$ & $\begin{array}{l}\text { Relevance to Oral Health } \\
\text { Professionals }\end{array}$ & $\begin{array}{l}\text { Periodontal disease \& OSA, observable signs and } \\
\text { symptoms }\end{array}$ \\
\hline $2: 24$ & $\begin{array}{l}\text { OSA Methods of Definitive } \\
\text { Diagnosis }\end{array}$ & Polysomnography and portable monitors \\
\hline $7: 20$ & OSA Treatment Options & $\begin{array}{l}\text { Positive airway pressure, oral devices, and surgical } \\
\text { treatment }\end{array}$ \\
\hline $20: 20$ & OSA Screening Methods & $\begin{array}{l}\text { Berlin Questionnaire, Epworth Sleepiness Scale, } \\
\text { STOP-BANG Questionnaire, Wisconsin Sleep } \\
\text { Questionnaire, video demonstration of screening } \\
\text { methods, capability of DH to screen, OSA referral } \\
\text { process }\end{array}$ \\
\hline $7: 31$ & OSA Case Study & OSA case study utilizing screening questionnaires \\
\hline \multicolumn{3}{|c|}{ Total Time: $1: 04: 38$} \\
\hline
\end{tabular}

narration of the presentation. To increase accessibility, the primary investigator converted the narrated PowerPoint into a video and uploaded it to YouTube.

To assess change in knowledge, a paired $t$ test determined whether a statistically significant difference occurred between mean pretest and posttest scores. Similarly, McNemar tests with exact $p$ values assessed change in knowledge for each individual question from pretest to posttest. To assess knowledge retention, a paired $t$ test determined whether a statistically significant difference occurred between the mean of the first and second posttest scores. A two-sample $t$ test ascertained whether an association existed between pretest scores and immediate family history of OSA. Measures of central tendency analyzed results from the program evaluation. Last, thematic qualitative analysis identified prominent themes from open-ended questions added to the posttest. The accepted level of statistical significance was $p<.05$.

\section{RESULTS}

The mean pretest score was $8.30(48.84 \%$, standard deviation $[\mathrm{SD}]=2.88)$, the mean first posttest score was $13.61(80.04 \%, \mathrm{SD}=1.77)$, and the mean second posttest score was $12.74(74.79 \%, S D=2.51)$. A paired $t$ test found a statistically significant increase from the mean pre-test score to the mean first posttest score $(p<.001, t(33)=$ 9.836). A statistically significant increase in correct responses per question occurred from the pretest to the first posttest in 10 of 17 questions $(p<.05)$. Only one question had a lower number of correct responses in the post-test compared to the pretest. Table 4 summarizes results of individual questions on the pretest compared to the first posttest. There was a statistically significant decrease from the mean first posttest score to the mean second posttest score $(p<.05, t(28)=2.214)$. A statistically significant increase resulted from the mean pretest score to the mean second posttest score $(p<.001, t(28)=5.653)$.

Twenty-two percent of participants $(n=7)$ who completed the demographic questionnaire $(n=32)$ indicated that OSA had been diagnosed in a member of their immediate family. The mean pretest score for participants who indicated a family history of OSA was 9.29 (54.62\%), compared to a mean pretest score of 8.00 (47.06\%) for participants who did not. A two-sample $t$ test concluded there was no detectable difference in mean pretest scores between participants with family history of OSA and participants without $(p=0.45)$. This conclusion is ambiguous because of the limited power of the test. Ninety-six percent of participants $(n=26)$ who completed the program evaluation indicated they agree or strongly agree the program content was appropriate to their level of understanding and provided participants with the information they need to screen patients for OSA. Eightone percent of participants $(n=22)$ indicated they agree or strongly agree the program material was presented in a way 
Table 3. Obstructive sleep apnea retest/posttest content.

\begin{tabular}{|c|c|c|c|c|c|}
\hline No & Question & Option A & Option B & Option C & Option D \\
\hline 1 & $\begin{array}{l}\text { As determined by polysomnography, an apnea- } \\
\text { hypopnea index of } 15-29 \text { respiratory events per hour } \\
\text { indicates: }\end{array}$ & Mild OSA & Moderate OSA & Severe OSA & No diagnosis \\
\hline 2 & The prevalence of OSA syndrome is: & Higher in men & $\begin{array}{l}\text { Higher in } \\
\text { women }\end{array}$ & $\begin{array}{l}\text { Equally } \\
\text { common }\end{array}$ & \\
\hline 3 & $\begin{array}{l}\text { Which of the following is NOT an adverse health } \\
\text { condition associated with OSA? }\end{array}$ & Hypertension & Type II diabetes & Alopecia & $\begin{array}{l}\text { Coronary heart } \\
\text { disease }\end{array}$ \\
\hline 4 & $\begin{array}{l}\text { Which of the following is NOT a risk factor for } \\
\text { OSA? }\end{array}$ & Menopause & Female sex & Obesity & $\begin{array}{l}\text { African } \\
\text { American race }\end{array}$ \\
\hline 5 & $\begin{array}{l}\text { Regarding Mallampati classification, an individual is } \\
\text { categorized as class III when the soft palate is not } \\
\text { visible. Mallampati class III is considered high risk } \\
\text { for OSA. }\end{array}$ & $\begin{array}{l}\text { The first statement } \\
\text { is true and the } \\
\text { second is false }\end{array}$ & $\begin{array}{l}\text { The first } \\
\text { statement is } \\
\text { false and the } \\
\text { second is true }\end{array}$ & $\begin{array}{l}\text { Both statements } \\
\text { are true }\end{array}$ & $\begin{array}{l}\text { Both statements } \\
\text { are false }\end{array}$ \\
\hline 6 & $\begin{array}{l}\text { Which of the following is considered to be the "gold } \\
\text { standard" diagnostic test for OSA? }\end{array}$ & Portable monitors & Berlin Quest. & $\begin{array}{l}\text { Polysomnogra- } \\
\text { phy }\end{array}$ & $\begin{array}{l}\text { STOP-BANG } \\
\text { Quest. }\end{array}$ \\
\hline 7 & $\begin{array}{l}\text { Current research suggests that OSA treatment with } \\
\text { positive airway pressure devices is superior to } \\
\text { treatment with mandibular advancement devices. } \\
\text { Oral devices are typically recommended for } \\
\text { individuals with mild to moderate OSA and poor } \\
\text { adherence to positive airway pressure devices. }\end{array}$ & $\begin{array}{l}\text { The first statement } \\
\text { is true and the } \\
\text { second is false }\end{array}$ & $\begin{array}{l}\text { The first } \\
\text { statement is } \\
\text { false and the } \\
\text { second is true }\end{array}$ & $\begin{array}{l}\text { Both } \\
\text { statements are } \\
\text { true }\end{array}$ & $\begin{array}{l}\text { Both statements } \\
\text { are false }\end{array}$ \\
\hline 8 & $\begin{array}{l}\text { Which of the following is the most accurate } \\
\text { questionnaire for predicting OSA diagnosis? }\end{array}$ & Berlin Quest. & $\begin{array}{l}\text { Epworth } \\
\text { Sleepiness } \\
\text { Scale }\end{array}$ & $\begin{array}{l}\text { STOP-BANG } \\
\text { Quest. }\end{array}$ & $\begin{array}{l}\text { Wisconsin } \\
\text { Sleep Quest. }\end{array}$ \\
\hline 9 & $\begin{array}{l}\text { Which of the following is the least accurate } \\
\text { questionnaire for predicting OSA diagnosis? }\end{array}$ & Berlin Quest. & $\begin{array}{l}\text { Epworth } \\
\text { Sleepiness } \\
\text { Scale }\end{array}$ & $\begin{array}{l}\text { STOP-BANG } \\
\text { Quest. }\end{array}$ & $\begin{array}{l}\text { Wisconsin } \\
\text { Sleep Quest. }\end{array}$ \\
\hline & & Case Study \#1 & & & \\
\hline 10 & $\begin{array}{l}\text { Which of the following significantly increases the } \\
\text { risk for OSA in this patient? }\end{array}$ & Occupation & Caucasian race & Age & Obesity \\
\hline 11 & $\begin{array}{l}\text { Which of the patient's health conditions is commonly } \\
\text { associated with OSA? }\end{array}$ & Hypertension & Type II diabetes & $\begin{array}{l}\text { Periodontal } \\
\text { disease }\end{array}$ & $\begin{array}{l}\text { All of the } \\
\text { above }\end{array}$ \\
\hline & & & & & $\begin{array}{l}\text { Option E: } \\
\text { Both A\&B }\end{array}$ \\
\hline 12 & $\begin{array}{l}\text { Based on the description provided, the patient has a } \\
\text { Mallampati classification of IV, which is considered } \\
\text { high risk for OSA. }\end{array}$ & $\begin{array}{l}\text { The first statement } \\
\text { is true and the } \\
\text { second is false }\end{array}$ & $\begin{array}{l}\text { The first } \\
\text { statement is } \\
\text { false and the } \\
\text { second is true }\end{array}$ & $\begin{array}{l}\text { Both statements } \\
\text { are true }\end{array}$ & $\begin{array}{l}\text { Both statements } \\
\text { are false }\end{array}$ \\
\hline 13 & $\begin{array}{l}\text { Based on the Berlin Questionnaire, the patient's risk } \\
\text { for OSA is: }\end{array}$ & High & Moderate & Low & \\
\hline & & Case Study \#2 & & & \\
\hline 14 & $\begin{array}{l}\text { Which of the following significantly increases the } \\
\text { risk for OSA in this patient? }\end{array}$ & Age & Female sex & Menopause & Both A\&C \\
\hline & & & & & $\begin{array}{l}\text { Option E: } \\
\text { All of the above }\end{array}$ \\
\hline 15 & $\begin{array}{l}\text { Which of the patient's health conditions is commonly } \\
\text { associated with OSA? }\end{array}$ & Hypothyroidism & $\begin{array}{l}\text { High blood } \\
\text { pressure }\end{array}$ & Anxiety & All of the above \\
\hline 16 & $\begin{array}{l}\text { Based on the description provided, the patient has a } \\
\text { Mallampati classification of II, which is considered } \\
\text { low risk for OSA. }\end{array}$ & $\begin{array}{l}\text { The first statement } \\
\text { is true and the } \\
\text { second is false }\end{array}$ & $\begin{array}{l}\text { The first } \\
\text { statement is } \\
\text { false and the } \\
\text { second is true }\end{array}$ & $\begin{array}{l}\text { Both } \\
\text { statements are } \\
\text { true }\end{array}$ & $\begin{array}{l}\text { Both statements } \\
\text { are false }\end{array}$ \\
\hline 17 & $\begin{array}{l}\text { Based on the STOP-BANG Questionnaire, the } \\
\text { patient's risk for OSA is: }\end{array}$ & High & Moderate & Low & \\
\hline \multicolumn{6}{|c|}{ Posttest Only } \\
\hline 1 & \multicolumn{5}{|c|}{$\begin{array}{l}\text { After completing the OSA educational module, do you believe screening for OSA is important? Why or why not? [free response } \\
\text { answer] }\end{array}$} \\
\hline 2 & \multicolumn{5}{|c|}{ What challenges do you anticipate in screening patients for OSA? [free response answer] } \\
\hline \multirow[t]{2}{*}{3} & \multicolumn{5}{|c|}{ After participating in this educational program, how likely are you to evaluate your adult patients for obstructive sleep apnea? } \\
\hline & \multicolumn{2}{|c|}{ Very Unlikely Unsure } & $\begin{array}{l}\text { Very likely } \\
5\end{array}$ & & \\
\hline
\end{tabular}

that helped participants learn. Only $37 \%(n=10)$ agreed or strongly agreed online learning was as effective as face-toface instruction.
The first open-ended question added to the first posttest asked participants following completion of the OSA educational module if they think screening for OSA 
Table 4. Individual question pretest to first posttest results

\begin{tabular}{|c|c|c|c|}
\hline Question & $\begin{array}{l}\text { Pretest } \\
\text { correct } \\
\text { response }\end{array}$ & $\begin{array}{l}\text { First } \\
\text { posttest } \\
\text { correct } \\
\text { response }\end{array}$ & $\begin{array}{l}\text { Exact } \\
\text { McNemar } \\
p \text { value }\end{array}$ \\
\hline Q1 - Severity & 15 & 29 & 0.0013 \\
\hline Q2 - Prevalence & 20 & 32 & 0.0005 \\
\hline Q3 - Associated adverse health conditions & 21 & 30 & 0.0117 \\
\hline Q4 - Risk factors & 12 & 31 & 0.0000 \\
\hline Q5 - Mallampati classification & 9 & 24 & 0.0007 \\
\hline Q6 - Diagnostic tests & 24 & 29 & 0.2668 \\
\hline Q7 - Treatment options & 17 & 26 & 0.0490 \\
\hline Q8 - Most accurate screening questionnaire & 19 & 25 & 0.1460 \\
\hline Q9 - Least accurate screening questionnaire & 11 & 29 & 0.0003 \\
\hline Q10 - Case study: risk factors & 31 & 33 & 0.5 \\
\hline Q11 - Case study: adverse health conditions & 10 & 12 & 0.8036 \\
\hline Q12 - Case study: Mallampati classification & 12 & 28 & 0.0004 \\
\hline Q13 - Case study: risk level (Berlin Questionnaire) & 11 & 28 & 0.0000 \\
\hline Q14 - Case study: risk factors & 17 & 23 & 0.1460 \\
\hline Q15 - Case study: adverse health conditions & 18 & 24 & 0.1460 \\
\hline Q16 - Case study: Mallampati classification & 21 & 19 & 0.8036 \\
\hline Q17 - Case study: risk level (STOP-BANG Questionnaire) & 6 & 27 & 0.0000 \\
\hline
\end{tabular}

is important. All participants $(n=33)$ indicated they think screening for OSA was important. Prominent themes identified included the following: dental hygienists being in a position to screen for OSA, the influence OSA has on oral and systemic health, patients being unaware of OSA risk, and the potential for OSA treatment to improve quality of life. The second open-ended question asked participants what challenges they anticipate in screening patients for OSA. Prominent themes identified included limited time, patients being unaware of sleep habits, accuracy of self-reported data, lack of credibility of dental hygienists to complete OSA screening, and difficulty determining which OSA screening method to use. Last, a Likert-type question, added to the first posttest, asked participants how likely they are to evaluate their adult patients for OSA following the educational module. Seventy-six percent of participants $(n=25)$ indicated they were likely or very likely to evaluate adult patients for OSA, and $24 \%(n=8)$ indicated they were unsure.

\section{DISCUSSION}

The results of this study provided statistically significant data that support an online educational intervention that can significantly increase the knowledge of information relevant to OSA screening in DH students. Results suggest an overall increase of OSA knowledge in participants based on both first and second posttest scores compared to pretest scores.

\section{Individual Questions}

Two questions that did not have a statistically significant increase in correct response also experienced a high percentage of correct responses on the pretest, which suggests prior knowledge of the information. The questions asked participants to identify polysomnography as the "gold standard" test for OSA, and obesity as a risk factor for OSA. The high percentage of correct pretest responses to these questions left minimal margin for statistically significant improvement. Nonsignificant knowledge changes in other questions may have been attributed to the wording of the questions or nominal differences in OSA classification categories. This suggests minimal time should be dedicated to commonly known OSA content. Despite select questions not demonstrating statistically significant changes in correct responses, overall results demonstrate a statistically significant $(p<$ .001) change in mean pretest to first posttest scores.

\section{Family History of OSA}

Twenty-two percent of participants $(n=7)$ who completed the demographic questionnaire indicated they 
had an immediate family history of OSA. This is comparable to data that estimated $26 \%$ of individuals aged 30 to 70 years between 2007 and 2010 had some degree of OSA. ${ }^{8}$ Although the mean pretest score for participants who indicated a family history of OSA was slightly higher compared to the mean pretest score for individuals without, there was no statistically significant difference detected. This finding suggests that a family history of OSA does not significantly increase knowledge of the condition, which is potentially common among healthcare practitioners. This infers dental and allied dental educators should not assume family history alone is sufficient to prepare OHPs to identify OSA.

\section{Program Evaluation}

The statistically significant increase in mean first posttest scores compared to pretest scores is supported by participants who indicated they agree or strongly agree the program content was appropriate to their level of understanding and indicated they agree or strongly agree program material was presented in a way that helped them learn. Despite this, most participants did not agree or strongly agree online learning was as effective as face-toface instruction. This is contradictory to a 2013 metaanalysis that found the mean effect sizes between purely online versus face-to-face instruction are not significantly different. ${ }^{9}$ This study also found a blended online and faceto-face instructional method positively influences student learning outcomes. ${ }^{9}$ This is similar to the flipped classroom pedagogy of the DH course where students completed the OSA educational module. These participants accustomed to a blended online and face-to-face instructional style may not value the purely online delivery style of the OSA educational module because of the lack of face-to-face interaction to which they are accustomed.

Furthermore, low self-efficacy with online learning may negatively influence student perception of ability to complete OSA screening in clinical practice. A 2014 article discussed strategies to promote student self-efficacy in the online classroom. ${ }^{10}$ This article referenced research by Albert Bandura (1997), who suggests there are four factors that affect an individual's self-efficacy: experience of mastery, vicarious experience, social persuasion, and physiological factors. ${ }^{10}$ The online OSA education module does not address these four factors, particularly the experience of mastery. The educational module did not facilitate the opportunity for participants to apply the knowledge, which may establish a sense of mastery of the skill. Inclusion of an application exercise may increase students' appreciation of online learning if they have opportunities to master the concept of OSA screening. The addition of simulation, role-playing, or standardized patients in future implementations of an OSA educational module may prove beneficial for educators charged with educating OHPs on OSA.

\section{Open-Ended Questions}

All participants $(n=33)$ believed OSA screening was important for the following reasons: dental hygienists are in a position to screen for OSA, OSA has an influence on oral and systemic health, patients are unaware of OSA risk, and the potential for OSA treatment to improve quality of life. These themes compare to those identified in a 2015 literature review that discusses the effect of OSA on systemic health, as well as the association between OSA and periodontal disease. ${ }^{5}$ These themes are further supported by the $76 \%$ of participants $(n=25)$ who indicated they are likely or very likely to screen their adult patients for OSA. This affects the dental and allied dental professions as it further expands expectations of providing oral health care and promoting overall health of patients. Furthermore, focusing on the provision of comprehensive care supports educating all OHPs to exercise critical thinking and focus on the entire process of care and not only traditional technical skills.

Prominent themes identified by participants regarding challenges they anticipate in screening patients for OSA included limited time for screening, patients being unaware of sleep habits, accuracy of self-reported data, lack of credibility of dental hygienists to complete OSA screening, and difficulty determining which OSA screening method to use. Lack of time to complete an OSA screening was one of the most prominent themes identified. A recent article compared expected duties of a dental hygienist in 1972 as opposed to 2015 , as well as the typical amount of time allocated for appointments. ${ }^{11}$ This article discussed dental hygienists in 2015 are expected to complete considerably more tasks in the same amount of time, including the expectation to discuss risk factors to systemic medical conditions. ${ }^{11}$ This increase in expectations illustrates why students may anticipate lack of time being a major challenge in screening for OSA. To combat this anticipated challenge, educators should promote students becoming familiar with prominent OSA questionnaires, therefore developing clinicians capable of conducting time-efficient screenings.

Because a significant number of prominent OSA questionnaires rely on self-reported data, the accuracy of self-reported data was also an anticipated challenge of participants. Although research has not been conducted on the accuracy of self-reported data for these specific questionnaires, there is research to support general inaccuracy of self-reported data. Furthermore, the National Sleep Foundation acknowledges snorers are generally unaware of their snoring. ${ }^{12}$ However, the potential benefit of OSA screening, even with false-negative results because of inaccurate self-reported data, far outweighs any disadvantages. It is important to recognize OSA screening is not a definitive diagnosis and further diagnostic tests are required. Screening questions on medical histories and a 
Table 5. Quality of obstructive sleep apnea (OSA) screening questionnaires

\begin{tabular}{|c|c|c|c|c|}
\hline \multirow[t]{2}{*}{$\begin{array}{l}\text { Questionnaire } \\
\text { Title }\end{array}$} & \multicolumn{3}{|c|}{$\begin{array}{l}\text { Systematic Review (Abrishami et al. 2010) } \\
\text { (Individuals without history of sleep disorders) } \\
\text { (Indiver }\end{array}$} & \multirow{2}{*}{$\begin{array}{l}\text { Meta-Analysis } \\
\text { (Ramachandran } \\
\text { and Josephs 2009) }\end{array}$} \\
\hline & $\begin{array}{l}\text { Slight OSA } \\
(\mathrm{AHI} / \mathrm{AI} \text { or } \mathrm{RDI} \geq \\
\text { 5) }\end{array}$ & $\begin{array}{l}\text { Moderate OSA } \\
(\mathrm{AHI} / \mathrm{AI} \text { or } \mathrm{RDI} \geq \\
15)\end{array}$ & $\begin{array}{l}\text { Severe OSA } \\
(\mathrm{AHI} / \mathrm{AI} \text { or } \mathrm{RDI} \geq \\
30)\end{array}$ & \\
\hline $\begin{array}{l}\text { Berlin } \\
\text { Questionnaire }\end{array}$ & Highest specificity & Highest specificity & Highest specificity & $\begin{array}{l}\text { Most accurate } \\
\text { questionnaire for } \\
\text { predicting OSA } \\
\text { diagnosis }\end{array}$ \\
\hline $\begin{array}{l}\text { STOP-BANG } \\
\text { Questionnaire }\end{array}$ & -------- & Highest sensitivity & Highest sensitivity & $\begin{array}{l}\text { Excellent method } \\
\text { for predicting } \\
\text { severe OSA }\end{array}$ \\
\hline $\begin{array}{l}\text { Wisconsin } \\
\text { Sleep } \\
\text { Questionnaire }\end{array}$ & \multicolumn{3}{|l|}{ Highest sensitivity } & $\begin{array}{l}\text { Not included in } \\
\text { meta-analysis }\end{array}$ \\
\hline $\begin{array}{l}\text { Epworth } \\
\text { Sleepiness } \\
\text { Scale (ESS) }\end{array}$ & \multicolumn{3}{|c|}{ Not included in systematic review } & $\begin{array}{l}\text { Least accurate } \\
\text { questionnaire for } \\
\text { predicting OSA } \\
\text { diagnosis }\end{array}$ \\
\hline \multicolumn{5}{|c|}{$\begin{array}{l}\text { Content adapted from referenced resources. }{ }^{15,19} \text { The proceeding questionnaires are not validated for use in } \\
\text { general practice of dentistry; thus, diagnostic sensitivity and specificity are unknown for populations of } \\
\text { dental patients. }\end{array}$} \\
\hline
\end{tabular}

reliable referral system are crucial if OSA is suspected.

Another prominent challenge identified by participants was a perceived lack of credibility of DHs to screen for OSA. Although there is no current research that demonstrates the competence of OHPs in screening for OSA, there are several published articles to suggest DHs are capable of screening for OSA. One author suggested dental hygienists are at a pivotal position to contribute interprofessionally to the screening of OSA. ${ }^{5}$ Another made the appeal that dental hygienists are "on the frontline regarding prevention and counseling". ${ }^{6}$ Last, it was stated that "dental hygienists as oral health educators have a unique opportunity to assess the deviations from normal that may alert the dentist that a sleep referral is indicated". ${ }^{13}$ As more dental and allied dental education programs incorporate OSA education into the curriculum, the credibility for OHPs to screen for this condition may increase. As with all systemic conditions, as patients become aware of OSA, they see OHPs as credible in discussing nonoral conditions. Dental educators must prepare OHPs to fulfill this role and promote the importance of holistic care.

A prominent theme identified was the difficulty in selecting an appropriate OSA screening method. The quality of OSA screening methods is summarized in Table
5. The research surrounding the quality of screening questionnaires may lead to confusion in determining which questionnaire to use. Based on current literature, the BQ is most specific for all severities of OSA, whereas the STOPBANG questionnaire is most sensitive for moderate to severe OSA. ${ }^{13}$ Therefore, content on how to use these two questionnaires along with opportunities to practice with each OSA screening method may improve the knowledge and experience of OHPs to select the most appropriate screening questionnaire and thus raise their self-confidence in conducting an OSA screening.

\section{Knowledge Retention}

Based on the participants who completed the second posttest $(n=28)$, a statistically significant decrease from first posttest to second posttest was detected $(p<.05)$. It can be speculated that some knowledge loss is anticipated, as participants completed the first posttest immediately after having access to the OSA educational video and completed the second posttest 2 weeks after completion of the educational module. It is important to note that despite a statistically significant decrease in mean scores from first to second posttest $(p<.05)$, there was still a statistically significant increase in mean scores from pretest to second 
posttest $(p<.001)$. These results are supported by a study that investigated knowledge loss of medical students from first-year basic science courses. ${ }^{15}$ This study recruited second-year medical students to retake test questions from their first year and compared the results to their original scores. This study found a statistically significant main effect of knowledge loss $(p<.001)$, demonstrating some degree of knowledge loss is anticipated in healthcare education. ${ }^{15}$ To combat anticipated knowledge loss, educators may consider OSA screening as a required competency or develop supplemental simulation or roleplaying scenarios.

\section{Limitations}

This study was limited by the sample size, missing data, and research methods. Due to convenience sampling, results of this study have limited generalizability because it is unknown whether this sample is representative of the entire DH student population. Furthermore, it is unknown if the sample is representative of DH students in other stages of their education, as only first-year DH students were invited to participate. Although the number of participants who completed the pretest and first posttest $(n=33)$ exceeded the number of participants needed for the results to be $80 \%$ with a $95 \%$ confidence level, the response rates on the demographic questionnaire $(n=32)$, program evaluation $(n=27)$, and second posttest $(n=28)$ could be considered a limitation.

\section{Recommendations/Suggestions for Future Research}

Studies using a more diverse sample of students would improve generalizability of results. Future variations of the online OSA educational module should consider combining assessments in an effort to increase complete participation and changing assessment settings to require responses. Investigation of an online educational module for other healthcare professionals would increase the validity and generalizability of the educational strategy. As the primary role of OSA screening is referral, research regarding interprofessional education of OSA among healthcare professions may illustrate a need for healthcare professionals competent in working interprofessionally. Additional areas to explore include evaluating the length and content of the educational intervention. Investigation into the use of online active learning strategies, such as interactive case studies or synchronous webinars, may demonstrate potential avenues to improve participant knowledge gain and retention. It may also be beneficial to investigate the value of requiring application of OSA knowledge in the curriculum, such as a clinical requirement to screen clinical patients for OSA.

Last, research is needed to determine if online OSA educational interventions significantly increase the number of individuals screened and referred for OSA diagnosis. Because the goal of this research is to investigate strategies that have the potential to increase OSA screening, it is important to consider whether completion of an online OSA educational module actually results in increased screening, referral, and diagnosis. More specifically, research to determine the proportion of individuals who were screened and referred for OSA in whom a positive diagnosis was made and who underwent treatment would provide valuable information on the competence OHPs to accurately screen for OSA.

\section{CONCLUSION}

The results of this study demonstrate that an online educational intervention can significantly increase the knowledge of information relevant to OSA screening in DH students. Furthermore, participants retained a significant amount of the OSA knowledge gained. Qualitative data suggest that DH students find OSA screening important. An online educational module has potential to improve OHPs' knowledge of OSA knowledge, resulting in increased screening and treatment for OSA and thus improved health outcomes.

\section{ACKNOWLEDGMENTS}

We would like to thank Dr. Nate Skuza for statistical guidance and Dr. Erin Elliott for expertise in OSA content. We also would like to thank Dr. Teresa Valerio, DNP, APN, FNP-BC, CSBM for the permission to adapt her research study of an OSA educational module for nurse practitioners to a comparable research study for DHs.

\section{ABBREVIATIONS}

BQ: Berlin Questionnaire

DH: dental hygiene

ESS: Epworth Sleepiness Scale

EWU: Eastern Washington University

OHP: oral health professional

OSA: obstructive sleep apnea

\section{REFERENCES}

1. Pottle K. Obstructive sleep apnea educational intervention of dental hygiene students. [master's thesis]. Cheney, WA: Eastern Washington University; 2017.

2. Epstein LJ, Kristo D, Strollo PJ Jr, et al. Clinical guideline for the evaluation, management and long-term care of obstructive sleep apnea in adults. J Clin Sleep Med. 2009;5(3):263-276.

3. Lee W, Nagubadi S, Kryger MH, Mokhlesi B. Epidemiology of obstructive sleep apnea: a population-based perspective. Expert Rev Respir Med. 2008;2(3):349-364.

4. Al-Jewair TS, Al-Jasser R, Almas K. Periodontitis and obstructive sleep apnea's bidirectional relationship: A systematic review and meta-analysis. Sleep Breath. 2015;19(4):1111-1120. 

dental hygienists. J Dent Hyg. 2015;89(5):285-292.

6. Minichbauer B. Sleep medicine content in dental hygiene education [Master of Dental Hygiene Education]. University of North Carolina at Chapel Hill; 2014.

7. Valerio TD, Heaton K. The effects of an online educational program on nurse practitioners' knowledge of obstructive sleep apnea in adults. J Am Assoc Nurse Pract. 2014;26(11):603-611.

8. Peppard PE, Young T, Barnet JH, Palta M, Hagen EW, Hla KM. Increased prevalence of sleep-disordered breathing in adults. Am J Epidemiol. 2013;177(9):1006-1014.

9. Means B, Toyama Y, Murphy R, Baki M. The effectiveness of online and blended learning: A meta-analysis of the empirical literature. Teachers College Record. 2013;115:1-47.

10. Vilkas B, McCabe C. Promoting students' self-efficacy in the online classroom. Faculty Focus. 2014.

11. Forbes KS. The 60-minute hygiene appointment: The procedures pile up; time allotted for them doesn't. $R D H$. 2015:24-28.

12. National Sleep Foundation. Snoring and sleep. https://sleepfoundation.org/sleep-disorders-problems/other-sleepdisorders/snoring/page/0/1. Updated 2017.

13. Fabbie P. Myofunctional analysis and its role in dental assessments and oral health. $R D H .2015 ; 35(8): 77-85$.

14. Abrishami A, Khajehdehi A, Chung F. A systematic review of screening questionnaires for obstructive sleep apnea. Can J Anesth. 2010;57(5):423-438.

15. D'Eon MF. Knowledge loss of medical students on first year basic science courses at the University of Saskatchewan. BMC Med Educ. 2006;6(5).
16. Ulasli SS, Gunay E, Koyuncu T, et al. Predictive value of Berlin Questionnaire and Epworth Sleepiness Scale for obstructive sleep apnea in a sleep clinic population. Clin Respir J. 2014;8(3):292-296.

17. Nagappa M, Liao P, Wong J, et al. Validation of the STOP-bang questionnaire as a screening tool for obstructive sleep apnea among different populations: A systematic review and meta-analysis. PLoS One. 2015;10(12):e0143697.

18. Young T. Rationale, design and findings from the Wisconsin Sleep Cohort Study: Toward understanding the total societal burden of sleep disordered breathing. Sleep Med Clin. 2009;4(1):37-46.

19. Ramachandran SK, Josephs LA. A meta-analysis of clinical screening tests for obstructive sleep apnea. Anesthesiology. 2009;110(4):928939.

\section{SUBMISSION \& CORRESPONDENCE INFORMATION}

\section{Submitted for publication November 1, 2018 Submitted in final revised form March 2, 2019 Accepted for publication March 5, 2019}

Address correspondence to Kathrine Glueckert, RDH, MSDH, 803 Pollux Road, Helena, MT, 59602, Phone: $307-$ 679-6033, Email: katie.pottle@gmail.com

\section{DISCLOSURE STATEMENT}

The authors have no conflicts of interest to disclose. 